\title{
An indoor environment evaluation by gender and age using an advanced personalized ventilation system
}

Abstract: In a closed space appropriate thermal comfort and proper indoor air quality are extremely important in order to obtain optimal work performance and to avoid health problems of the occupants. Using advanced personalized ventilation systems, different comfort needs can be locally satisfied even in case of warm environments. Thermal sensation and the subjective evaluation of indoor air quality of young and elderly people, men and women respectively, were studied in warm environment using advanced personalized ventilation system combined with total volume ventilation system. Using an advanced personalized ventilation system $20 \mathrm{~m}^{3} \cdot \mathrm{h}^{-1}$ air flow was alternately introduced by three air terminal devices built-in the desk and placed on a horizontal plane at the head level of the sitting subject. Thermal sensation was significantly cooler in case of young women in comparison with the other groups. Odour intensity was evaluated significantly lower in case of elderly women in comparison with the other groups. Evaluation of air freshness is in correlation with the general thermal sensation. Variation of the direction of the air velocity vector has a cooling side effect, which, in warm environments, might be useful in order to improve the thermal comfort sensation.

Keywords: thermal sensation, warm environment, gender, age, indoor air quality, air velocity vector

Practical implication: From the basic factors that influence the thermal comfort sensation, air velocity is the one and only parameter that must be treated as a vector. The air flow velocity has an important effect on the convective heat quantity released by the human body, but the 
changes in the air velocity direction have a cooling side effect. This cooling side effect should be exploited properly in warm environments by advanced PV systems to improve the thermal comfort sensation of the occupants without supplementary energy use.

\section{Introduction}

People have various thermal comfort needs and using traditional ventilation systems with total volume air distribution (TVAD) it is difficult to fulfil in each point of a closed space the comfort requirements established in standards. This challenge is accentuated by the ever changed solar radiation entering through the transparent surfaces of the building envelope. Personalized ventilation (PV) systems can create a user specific, "on demand" microenvironment in a certain location of a closed space. PV has the advantage that each occupant is authorized to optimize and control the temperature, flow rate (local air velocity) and direction of the locally supplied air flow, [1]. According to Melikov the focus must be shifted from TVAD to advanced air distribution (AAD) based on the following principles, [2]:

- remove/reduce the air pollution and generated heat (when not needed) locally;

- provide clean air, also heating and cooling, where, when, and as much as needed;

- make possible active control of the air distribution;

- involve each occupant in creating his/her own preferred microenvironment.

However, the air terminal devices (ATD) used at PV strongly influences the air distribution efficiency [3]. The perceived air quality is influenced by the ATD type, air flow rate and the distance between ATD and breathing zone [4]. The PV systems can be used alone or combined with TVAD systems and local heating or cooling solutions [5].

Draught is one of the most important issues, which must be treated carefully in case of PV. There is a strong relation between air turbulence intensity and sensation of draught [6]. Wang et al. involving subjects analysed the effects of turbulence intensity (15\% and $30 \%)$ on the 
subjective response to draught, [7]. They proved that the skin temperature drop was significantly larger in case of higher turbulence intensity and the percentage of dissatisfied subjects with draught positively correlated to the local skin temperature drop. Sun et al. analysed the general thermal sensation and facial thermal sensation under $23.5^{\circ} \mathrm{C}$ and $26{ }^{\circ} \mathrm{C}$ ambient conditions at two different turbulence intensities, [8]. They have found that at high turbulence intensities associated with low facial velocities range (up to $0.4-0.5 \mathrm{~m} / \mathrm{s}$ ) the facial thermal sensation votes are less cool. Depending on the used ventilation method in a closed space, turbulence intensity can have different values in different air layers in the occupational zone. Zhang et al. demonstrated that in highly stratified conditions the negative effects of vertical temperature air temperature differences may be neutralized by the different turbulence intensities in these air layers, [9]. Toftum and Nielsen shown that the draught sensitivity is influenced by general thermal sensation, [10]. They have established a relation between the relative increase in the percentage of dissatisfied persons due to draught at a cool thermal sensation in proportion to a neutral thermal sensation at equal mean air velocity. Inversely, in warm environment the elevated air velocity and higher turbulence intensity may help in obtaining the appropriate thermal comfort sensation, [11].

Experiments carried out in the Human Thermal Environments Laboratory at Loughborough University demonstrated that females tend to be cooler than males in cool conditions, [12]. The measurements conducted shown that this observation seems to be true for warm environments too. Furthermore, the increase of air velocity and the changing of air flow direction have a higher impact on the thermal comfort sensation in the case of female subjects. The metabolic heat production is different by gender and age and can have a strong influence in the perceived thermal sensation. The influence of metabolic heat production on the thermal comfort sensation was discussed by Havenith et al, [13]. The obtained results correlate with Indraganti's and Rao's findings too [14]. Based on field studies, they found that 
in hot and dry climate with seasonal variations the thermal acceptance of women, older subjects is higher. Choi et al. carried out a series of measurements in order to analyse the thermal satisfaction of occupants in office buildings, [15]. They found that females are more dissatisfied with their thermal environments than males especially in the summer. At first sight this statement seems to be in contradiction with the results of experiments performed, but Choi et al. specified that "females in the 'very dissatisfied" group experienced a mean temperature of $22.79{ }^{\circ} \mathrm{C}$ compared to $23.70{ }^{\circ} \mathrm{C}$ in the 'satisfied' group" Consequently, the dissatisfaction of female persons was caused by the lower mean temperature.

Air velocity is a vector defined by its magnitude and direction. At a certain operative temperature value, to identify the optimal air velocity-turbulence intensity combination to obtain proper thermal comfort without draught sensation, not only the mean value and the fluctuations of the air velocity have to be measured, but also the vector components should be identified, [16]. At University of Debrecen, a new personalized ventilation method and equipment (ALTAIR) was developed $[17,18]$ which permits the variation of air flow velocity direction around the head. This equipment exploits the fact that the response time to cold stimulus is shorter than the response time to a warm stimulus, $[19,20]$. Preventing adaptation in this way, a continuous cooling sensation is obtained, which can improve the thermal sensation in warm environments. Nevertheless, at ALTAIR PV system, at a certain operative temperature value, the identification of air flow velocity and rotational speed of air jet combinations, which lead to useful or harmful draught, is crucial. People are starting to work at the age of 25-30 years and the retirement is expected at 62-65 years. It was assumed that different age groups, men and women respectively, will perceive in a different way the effects of air movements in warm environment, so their thermal sensation will be different. Involving 20 elderly and 20 young persons (10 male and 10 female, respectively) two hours long measurements have been carried out in order to analyse the subjective thermal comfort 
sensation in warm environment using the ALTAIR PV system. Measurements have been performed in a test room, where all comfort parameters can be properly controlled. The comparison of subjective responses within and between the groups was done using ANOVA method. This paper summarizes the findings of this research.

\section{Hypothesis}

The main goal of this research work was to analyse the thermal sensation by gender and age of a warm indoor environment. Other objective was to see the effects of an advanced personalized ventilation system on thermal sensation of subjects in the warm environment. It was presumed that the occupants will evaluate the environment warm or hot. Furthermore, by moving the air around the head of occupants it was expected that the responses of subjects will decrease. The air flow direction was changed and it was presumed that at smaller time steps the thermal comfort sensation will be lower. The risk of this "cooling" method is the draught sensation. However, in the analysed warm environment, it was presumed that few persons will evaluate the draught as a discomfort factor.

\section{Methods}

\subsection{Test room}

In the Indoor Environmental Quality laboratory, the University of Debrecen there is an "adiabatic" room, which has its external building elements very well insulated $(\mathrm{U}=0.19 \mathrm{~W}$ $\left.\mathrm{m}^{-2} \mathrm{~K}^{-1}\right)$. In this external "adiabatic" room, the test room $(2.50 \times 3.65 \times 2.55 \mathrm{~m})$ is placed (Figure 1). The space between the walls of these rooms is divided into two temperature zones. There is an "outdoor" temperature zone, where temperatures in the range -20 to $34{ }^{\circ} \mathrm{C}$ can be produced. In the other zone are temperatures similar to the set point temperature in the test room. The test room can have one or two "external" walls. The test room also has an 
"external" window. The internal surface temperatures in the test room can be controlled having built in heating-cooling pipe loops. The total volume ventilation can be realized either by mixed or displacement air distribution mode. The mass flow and all other parameters of the fresh air can be controlled properly by the installed air handling unit.

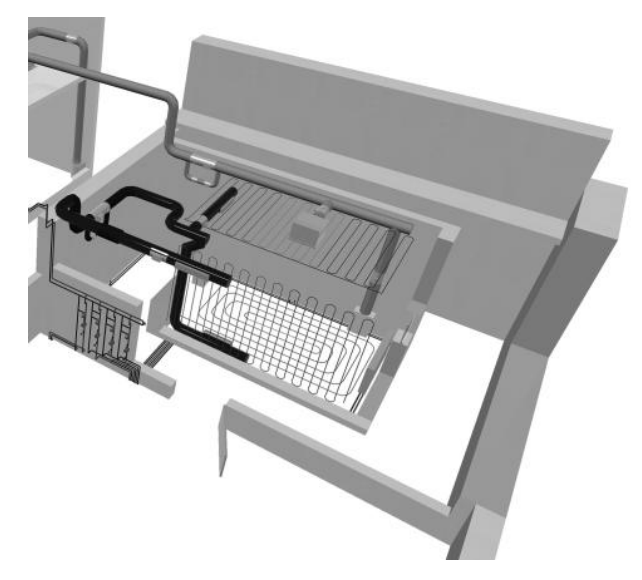

Figure 1. Test room (IEQ Laboratory)

During measurements the surface temperatures of the test room have been controlled in such a way that the mean radiant temperature in the middle of the room was constantly $30{ }^{\circ} \mathrm{C}$ during measurements. The indoor air temperature and the supplied air temperature were fixed to 30 ${ }^{\circ} \mathrm{C}$. Fresh air was assured continuously during the measurement $\left(50 \mathrm{~m}^{3} \cdot \mathrm{h}^{-1}\right)$, by displacement air distribution mode at $30{ }^{\circ} \mathrm{C}$ temperature. First and foremost, two hours long measurements have been performed without any subject. The ambient parameters have been registered minute by minute using a TESTO 480 instrument fixed in the middle of the room (the temperature, air velocity and relative humidity probes were measured at $1.1 \mathrm{~m}$ height). The mean value of the calculated PMV was 1.44, with a standard deviation $\mathrm{SD}=0.0317$.

\subsection{ALTAIR PV system}

The principle of the ALTAIR PV system is the variation of air-flow direction. The ventilated air can be introduced from three different directions and the air jet direction is continuously changed setting a certain time step desired by occupant (Figure 2). The air terminal devices 
are placed on a horizontal plane at $1.1 \mathrm{~m}$ height from the floor level. The air flow, which can be outdoor (fresh) air or simply the air from the room, is circulated through desk-built-in air channels and it is blown alternately from the left-front-right direction on the occupant. Consequently, the novelty of ALTAIR is the continuous stimulation of thermal receptors avoiding sensory accommodation, [14].

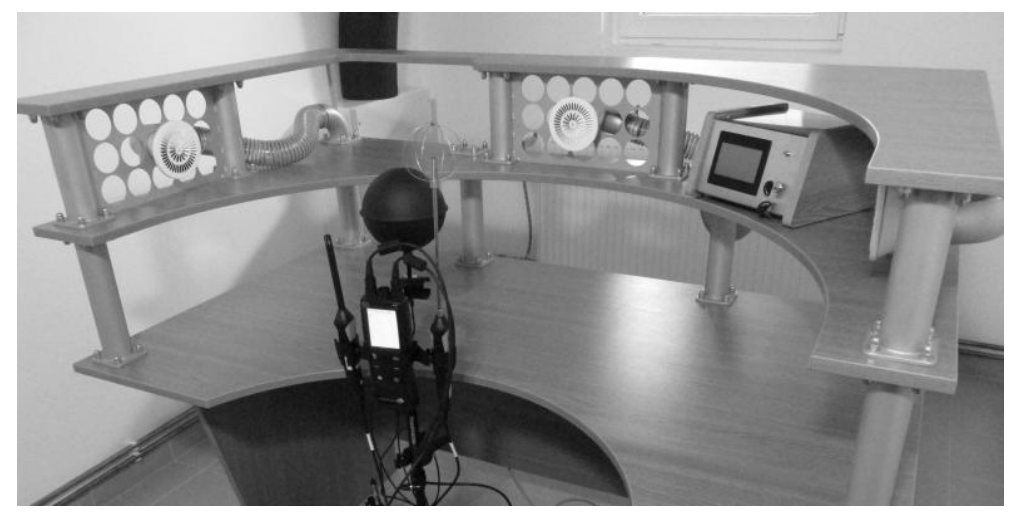

Figure 2. ALTAIR PV system

As air terminal devices circular perforated plastic panels were used ( $\mathrm{D}=75 \mathrm{~mm})$. ALTAIR has its own built-in fan and can be connected to the fresh air ducts or used only for the indoor air circulation. This time, during measurements ALTAIR was used combined with the displacement ventilation, so its role was only to move the air around the head of the subjects. ALTAIR has a built in air distribution box. The air may leave the box either through one, two or three tubular air channels. The opening/closing of air channels is controlled by electromagnetic valves. The operation mode is set on the control box before starting the ventilator. This time the air was blown onto the occupant at the head level sequentially from the left-front-right side. The time step of changing the air flow direction can be sat using the touch screen of the control box. The distance between the air terminal devices and subjects' head is $0.6 \mathrm{~m}$. The circulated air flow by ALTAIR was set to $20 \mathrm{~m}^{3} \cdot \mathrm{h}^{-1}$. The air flow was measured by using KIMO AMI 300, with K75 air flow cone. The air flow is fixed by choosing the right rotation speed of the ALTAIR built-in fan. This can be set plainly using the 
touch screen of the control box of the ALTAIR equipment. The mean air velocity obtained around the subjects head was $0.48 \mathrm{~m} \cdot \mathrm{s}^{-1}$. The turbulence intensity varies a little bit with the air flow direction changing time step: at $10 \mathrm{~s}$ was $\mathrm{Tu}_{10}=20.6 \%$, at $20 \mathrm{~s}, \mathrm{Tu}_{20}=19.1 \%$ at $30 \mathrm{~s}$, $\mathrm{Tu}_{30}=18.8 \%$. With ALTAIR PV in operation the PMV value shown by TESTO 480 instrument was 0.84 . Nevertheless, the instrument has omnidirectional air velocity probe, so the direction changing of the air flow velocity vector could not be taken into consideration.

\subsection{Instruments}

During experiments the following calibrated instruments were used:

- Globe temperature: TESTO SAVERIS, Globe probe $\varnothing 150 \mathrm{~mm}$, TC Type K, accuracy: \pm 1 ${ }^{\circ} \mathrm{C}$, placed in the middle of the room at $1.1 \mathrm{~m}$ height.

- Air temperature: TESTO SAVERIS, probe accuracy: $\pm 0.4{ }^{\circ} \mathrm{C}$, placed in the middle of the room at $1.1 \mathrm{~m}$ height.

- Relative humidity: TESTO 435, probe accuracy: $\pm 2 \% \mathrm{RH}(+2$ to $+98 \% \mathrm{RH})$, (placed in the middle of the room at $1.1 \mathrm{~m}$ height).

- Air speed was measured in the middle of the room at $1.1 \mathrm{~m}$ height: TESTO 435, probe accuracy: $\pm(0.03 \mathrm{~m} / \mathrm{s}+5 \%$ of measured value $)$.

- Turbulence intensity: TESTO 435, Comfort level probe for degree of turbulence measurement with telescopic handle $(\max .820 \mathrm{~mm}$ ) and stand, meets EN 13779 requirements, accuracy: $\pm(0.03 \mathrm{~m} / \mathrm{s}+4 \%$ of measured value $)$, measured in the middle of the room at $1.1 \mathrm{~m}$ height.

- Air flow in the ventilation system: KIMO AMI 300, with K75 air flow cone, probe accuracy: $\pm(0.03 \mathrm{~m} / \mathrm{s}+3 \%$ of measured value $)$

- $\mathrm{CO}_{2}$ concentration: TESTO 435, IAQ probe to assess indoor air quality, accuracy: $\pm(50 \mathrm{ppm}$ $\mathrm{CO}_{2} \pm 2 \%$ of $\left.\mathrm{mv}\right)\left(0\right.$ to $\left.+5000 \mathrm{ppm} \mathrm{CO}_{2}\right)$

- PMV: TESTO 480 instrument. 


\subsection{Subjects}

In order to assess the thermal comfort sensation in the test room, 20 young and 20 elderly Hungarian subjects were involved in the measurements (10 male and 10 female in each group). The anthropometric data of the subjects are shown in Table 1.

Table 1. Anthropometric data of the subjects

\begin{tabular}{|c|c|c|c|c|c|c|}
\hline Gender & Age group & Data type & Age, [y] & Weight, [kg] & Height, $[\mathrm{cm}]$ & $\mathrm{F}_{\mathrm{Du}},\left[\mathrm{m}^{2}\right]$ \\
\hline \multirow{4}{*}{ Female } & \multirow{2}{*}{ Young } & Mean & 25.5 & 61.9 & 166.1 & 1.687 \\
\hline & & SD & 5.4 & 13.1 & 7.3 & 0.257 \\
\hline & \multirow{2}{*}{ Elderly } & Mean & 59.1 & 70.9 & 161.2 & 1.749 \\
\hline & & SD & 3.0 & 10.9 & 4.6 & 0.110 \\
\hline \multirow{4}{*}{ Male } & \multirow{2}{*}{ Young } & Mean & 22.2 & 85.4 & $\begin{array}{l}181.9 \\
\end{array}$ & 2.068 \\
\hline & & SD & 2.7 & 12.7 & 5.5 & 0.121 \\
\hline & \multirow{2}{*}{ Elderly } & Mean & 55.2 & 91.8 & 181.4 & 2.121 \\
\hline & & SD & 3.6 & 24.3 & 3.9 & 0.177 \\
\hline
\end{tabular}

Before starting the measurements subjects were asked on their draught sensitivity and indoor temperature preference in summer. Their answers are presented in Table 2.

Table 2. Draught sensitivity and indoor temperature preference of the subjects

\begin{tabular}{|c|c|c|l|l|}
\hline \multirow{2}{*}{ Gender } & \multirow{2}{*}{ Age group } & \multirow{2}{*}{ Draught sens., [\%] } & \multicolumn{2}{|c|}{ Temperature preference $\left[{ }^{\circ} \mathrm{C}\right]$} \\
\cline { 4 - 5 } & & & Mean & SD \\
\hline \multirow{2}{*}{ Female } & Young & 60 & 25.5 & 1.72 \\
\cline { 4 - 6 } & Elderly & 60 & 24.5 & 1.51 \\
\hline \multirow{2}{*}{ Male } & Young & 20 & 24.2 & 2.04 \\
\cline { 2 - 5 } & Elderly & 40 & 23.8 & 1.48 \\
\hline
\end{tabular}




\subsection{Experimental procedure}

Measurements were conducted in June-July, 2015. Subjects were asked to arrive 30 minutes before starting the measurements. These 30 minutes were considered to be the acclimatisation period. Furthermore, in this period of time subjects were asked about their age, smoking habits, indoor temperature preference in summer period, draught sensitivity. The height, weight and blood pressure was measured. The questions they had to give responses during the measurements were explained in detail. Subjects were selected of people working or studying at the University of Debrecen, Faculty of Engineering. They were enlightened upon the heat exchange process, temperature scales, draught and asymmetric radiation.

During the two hours individual tests subjects sat at the ALTAIR desk in the middle of the test room. The TVAD system operates continuously during the measurement. The schedule of measurement was: 30 minutes only the TVAD was in operation. In the following 30 minutes the ALTAIR PV operates in combination with the TVAD. The time step of changing the air flow direction was set to $30 \mathrm{~s}$. In the next 30 minutes the time step of the ALTAIR was reduced to 20 second. Finally, in the last 30 minutes the time step was set to $10 \mathrm{~s}$. The air temperature, mean radiant temperature were kept constant during the two hours measurements. Subjects were not allowed to change their clothes during measurements. Water drinking was allowed but eating was not allowed. They could read, learn, solve exercises or play on their tablet. The clothing thermal insulation was 0.5 clo (ISO 9920:2007, Men: underpants, shirt with short sleeves, light trousers, light socks, shoes; Women: bra, panties, shirt with short sleeves, skirt, sandals) while the activity level was $70 \mathrm{~W} \cdot \mathrm{m}^{-2}$ (sedentary activity; ISO 8996:2004). Subjects undertook the tests randomized. They didn't know anything about the previous or the subsequent person. It was not permitted to attend the two tests on the same day. Subjects were not aware about the schedule of the tests and indoor parameters. Between two subsequent measurements at least two hours break was kept. During 
the first hour the test room was intensively ventilated $\left(500 \mathrm{~m}^{3} \cdot \mathrm{h}^{-1}\right)$ and in the next hour the initial indoor parameters were established in the test room. During measurement sessions, from 10 to 10 minutes, subjects were asked to complete a short questionnaire:

Q1. Evaluate the indoor environment on the following scales (Figure 3):

a) Mark on the 6 points scale the odour intensity in the room

b) Mark on the 7 points thermal comfort scale your thermal comfort sensation

c) Mark on the 3 points scale the acceptability of the environment

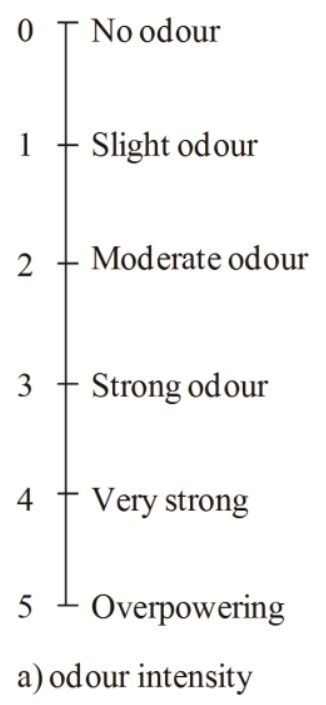

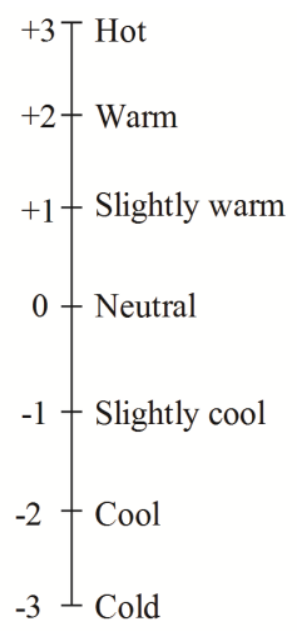

b) thermal sensation

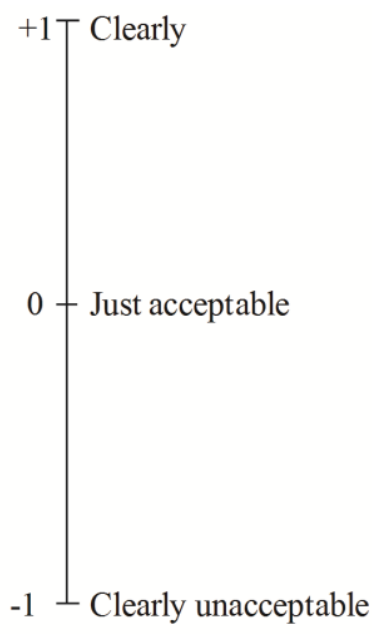

c) acceptability

Figure 3. Scales for indoor environment quality evaluation

Q2. Is the air velocity acceptable?

Yes

No

If not, what should do with it?

Increase

Decrease

Q3. Do you feel draught?

Yes

No

If your answer is Yes, please specify the body segment(s) you feel draught head neck arms back legs ankles

Q4. Are you content with the freshness of the indoor air? Yes No

Q5. Are you content with indoor surface temperatures? $\quad$ Yes No If not, what to do?

floor temperature: ceiling temperature: increase

increase decrease decrease 
walls temperature:

increase

decrease

(underline which wall temperature should be changed: front, back, left, right)

\section{Results and discussion}

\subsection{Thermal comfort sensation}

The mean values and the standard error of means (SEM) of the responses related to thermal comfort sensation by age and gender for different operation mode of the ALTAIR PV system (no operation, 30s, 20s, 10s time step of air flow direction changing) are presented in Figure 4.
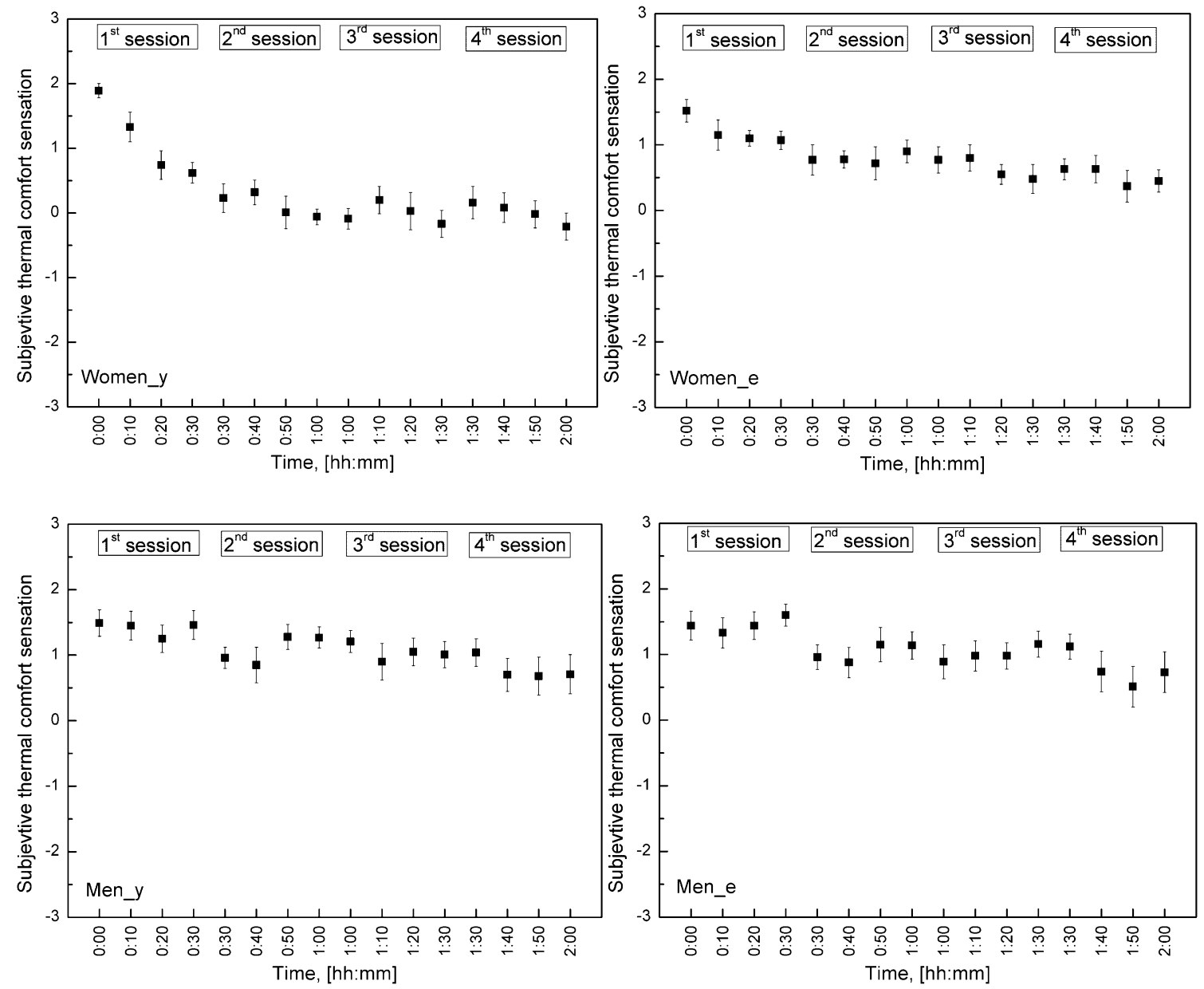

Figure 4. Subjective thermal comfort sensation by gender and age 
The means comparison of different groups was done using ANOVA method at a significance level $\mathrm{p}=0.05$. The results are presented in Table 3 .

Table 3. Comparison of analysed groups at 0.05 significance level

\begin{tabular}{|l|c|c|c|c|}
\hline \multicolumn{1}{|c|}{ Compared groups } & MeanDiff & q Value & Prob & Sig \\
\hline Women_y_10 s - Women_y_no & -1.14 & 10.370 & $9.82483 \mathrm{E}-9$ & 1 \\
\hline Women_y_10 s - Women_y_20 s & 0.01 & 0.090 & 1 & 0 \\
\hline Women_y_10 s - Women_y_30 s & -0.12 & 1.111 & 0.99999 & 0 \\
\hline Women_y_20 s - Women_y_no & -1.15 & 10.460 & $9.57628 \mathrm{E}-9$ & 1 \\
\hline Women_y_20 s - Women_y_30 s & -0.13 & 1.202 & 0.99997 & 0 \\
\hline Women_y_30 s - Women_y_no & -1.02 & 9.258 & $2.72668 \mathrm{E}-8$ & 1 \\
\hline Women_e_10 s - Women_e_no & -0.69 & 6.262 & 0.00121 & 1 \\
\hline Women_e_10 s - Women_e_20 s & -0.13 & 1.179 & 0.99998 & 0 \\
\hline Women_e_10 s - Women_e_30 s & -0.27 & 2.473 & 0.93269 & 0 \\
\hline Women_e_20 s - Women_e_no & -0.56 & 5.082 & 0.03036 & 1 \\
\hline Women_e_20 s - Women_e_30 s & -0.14 & 1.293 & 0.99993 & 0 \\
\hline Women_e_30 s - Women_e_no & -0.41 & 3.789 & 0.34615 & 0 \\
\hline Men_y_10 s - Men_y_no & -0.63 & 5.718 & 0.00593 & 1 \\
\hline Men_y_10 s - Men_y_20 s & -0.26 & 2.359 & 0.95412 & 0 \\
\hline Men_y_10 s - Men_y_30 s & -0.30 & 2.791 & 0.83903 & 0 \\
\hline Men_y_20 s - Men_y_no & -0.37 & 3.358 & 0.56751 & 0 \\
\hline Men_y_20 s - Men_y_30 s & -0.04 & 0.431 & 1 & 0 \\
\hline Men_y_30 s - Men_y_no & -0.32 & 2.927 & 0.78367 & 0 \\
\hline Men_e_10 s - Men_e_no & -0.67 & 6.149 & 0.00171 & 1 \\
\hline & -0.22 & 2.064 & 0.98636 & 0 \\
\hline & & & & \\
\hline & & & & \\
\hline & & & & \\
\hline
\end{tabular}




\begin{tabular}{|c|c|c|c|c|}
\hline Men_e_20 s - Men_e_no & -0.45 & 4.084 & 0.22391 & 0 \\
\hline Men_e_20 s-Men_e_30 s & -0.03 & 0.272 & 1 & 0 \\
\hline Men_e_30 s - Men_e_no & -0.42 & 3.812 & 0.33566 & 0 \\
\hline Women_e_no - Women_y_no & 0.06 & 0.589 & 1 & 0 \\
\hline Women_e_10 s - Women_y_10 s & 0.51 & 4.697 & 0.07182 & 0 \\
\hline Women_e_20 s - Women_y_20 s & 0.65 & 5.967 & 0.00292 & 1 \\
\hline Women_e_30 s - Women_y_30 s & 0.66 & 6.058 & 0.00224 & 1 \\
\hline Men_e_no - Women_y_no & 0.30 & 2.791 & 0.83903 & 0 \\
\hline Men_e_no - Women_e_no & 0.24 & 2.201 & 0.9751 & 0 \\
\hline Men_e_no - Men_y_no & 0.04 & 0.363 & 1 & 0 \\
\hline Men_e_10 s - Women_y_10 s & 0.77 & 7.0117 & $1.05192 \mathrm{E}-4$ & 1 \\
\hline Men_e_10 s - Women_e_10 s & 0.25 & 2.314 & 0.96111 & 0 \\
\hline Men_e_10 s-Men_y_10 s & -0.007 & 0.068 & 1 & 0 \\
\hline Men_e_20 s - Women_y_20 s & 1.01 & 9.167 & $3.47456 \mathrm{E}-8$ & 1 \\
\hline Men_e_20 s-Women_e_20 s & 0.35 & 3.199 & 0.65184 & 0 \\
\hline Men_e_20 s-Men_y_20 s & -0.04 & 0.363 & 1 & 0 \\
\hline Men_e_30 s - Women_y_30 s & 0.90 & 8.237 & $1.10471 \mathrm{E}-6$ & 1 \\
\hline Men_e_30 s-Women_e_30 s & 0.24 & 2.178 & 0.97736 & 0 \\
\hline Men_e_30 s-Men_y_30 s & -0.05 & 0.521 & 1 & 0 \\
\hline Men_y_no - Women_y_no & 0.26 & 2.428 & 0.94197 & 0 \\
\hline Men_y_no - Women_e_no & 0.20 & 1.838 & 0.99585 & 0 \\
\hline Men_y_10 s - Women_y_10 s & 0.78 & 7.079 & $8.30965 \mathrm{E}-5$ & 1 \\
\hline Men_y_10 s-Women_e_10 s & 0.26 & 2.382 & 0.9503 & 0 \\
\hline Men_y_20 s - Women_y_20 s & 1.05 & 9.530 & $1.61837 \mathrm{E}-8$ & 1 \\
\hline Men_y_20 s - Women_e_20 s & 0.39 & 3.562 & 0.45879 & 0 \\
\hline Men_y_30 s - Women_y_30 s & 0.96 & 8.758 & $1.41304 \mathrm{E}-7$ & 1 \\
\hline Men_y_30 s - Women_e_30 s & 0.29 & 2.700 & 0.87101 & 0 \\
\hline
\end{tabular}


Notations used in column heading:

MeanDiff - difference between means;

SEM - standard error of means;

$\mathrm{q}$ - value - critical value of studentized range distribution

Prob - significance level

$\mathrm{Sig}=1$ (the means are significantly different); $\mathrm{Sig}=0$ (the means are not significantly different)

It can be observed that at the beginning the responses of the young women group are the highest. Moving the air around the head of the occupants leads to significantly lower responses in case of each group in comparison with the first 30 minutes. However, there is no significant difference between the responses of elderly groups and the young men group. The responses of the young women group are significantly different by the responses of other groups. Hair plays an important role in the subjective thermal comfort sensation. In case of young women group only one person has very short haircut (covering a little bit the ears). All the other subjects have long hair (shoulder length hair). All subjects in the elderly women group have very short hair (a little bit on the ears). One man (elderly group) had long hair (pony tail hair style) and had short beard. One other person (elderly men group) had moustache. All other subjects in the men groups had very short hair; hadn't beard and hadn't moustache. It can be seen that young women, having longer hair, evaluated the thermal comfort with the lowest responses. In the case of ALTAIR the air is coming sequentially from left side-front-right side of the head (similarly to a hand held fan). The insulation effect of the hair in this case is reduced (practically the hair cannot protect the face from the air flow). In the case of first session of measurements (without ALTAIR PV system), the previously calculated PMV value (1.44) was validated by the young men, elderly men, elderly women group of subjects, while in the case of young women group the given answers related to the 
thermal comfort sensation were significantly lower, in spite of their 1.9 mean value given when the first session started (Table 4).

Table 4. Mean values of subjective thermal sensation by session and groups

\begin{tabular}{|c|c|c|c|c|}
\hline Session & Women_y & Women_e & Men_y & Men_e \\
\hline No ALTAIR & 1.15 & 1.21 & 1.41 & 1.45 \\
\hline $30 \mathrm{~s}$ & 0.13 & 0.79 & 1.09 & 1.03 \\
\hline $20 \mathrm{~s}$ & -0.01 & 0.65 & 1.04 & 1.00 \\
\hline $10 \mathrm{~s}$ & 0.00 & 0.52 & 0.78 & 0.78 \\
\hline
\end{tabular}

The measured PMV value with the ALTAIR PV in operation was 0.84 and this value was validated by the men groups in the last session. Both elderly and young women groups appreciated the environment colder than it was expected. Practically, using the ALTAIR PV equipment the percent of dissatisfied persons was lower than the calculated PPD (predicted percentage of dissatisfied). It is true, that the draught sensitivity was high in these groups. Furthermore, the preferred temperature in summer was higher in case of women, so it was expectable that these groups tolerates easier higher temperatures and they are more sensitive to air movements, then the male subjects.

It can be stated for all analysed subject groups, that the thermal sensation decreased at lower time steps of the ALTAIR PV system. This means that, at higher rotational speed of the air flow jet, the cooling sensation increased. It is interesting that, practically, age had no effect on the men's answers related to thermal sensation. Thermal sensation of young women subjects was significantly lower, in comparison with the answers of the other groups, in all measurement sessions, when ALTAIR PV was in operation. When the time step of changing the air flow direction was $10 \mathrm{~s}$, the thermal sensation was significantly lower in case all groups in comparison with the case when the ALTAIR PV was switched off. In case of 20 s time step both women groups gave significantly lower answers related to thermal sensation in comparison with case when ALTAIR PV was switched off. 


\subsection{Evaluation of odour intensity}

The mean values and the SEM of the odour intensity evaluation on the 6 points scale by age and gender for different operation mode of the ALTAIR PV system (no operation, 30s, 20s, 10s time step of air flow direction changing) are presented in Figure 5.
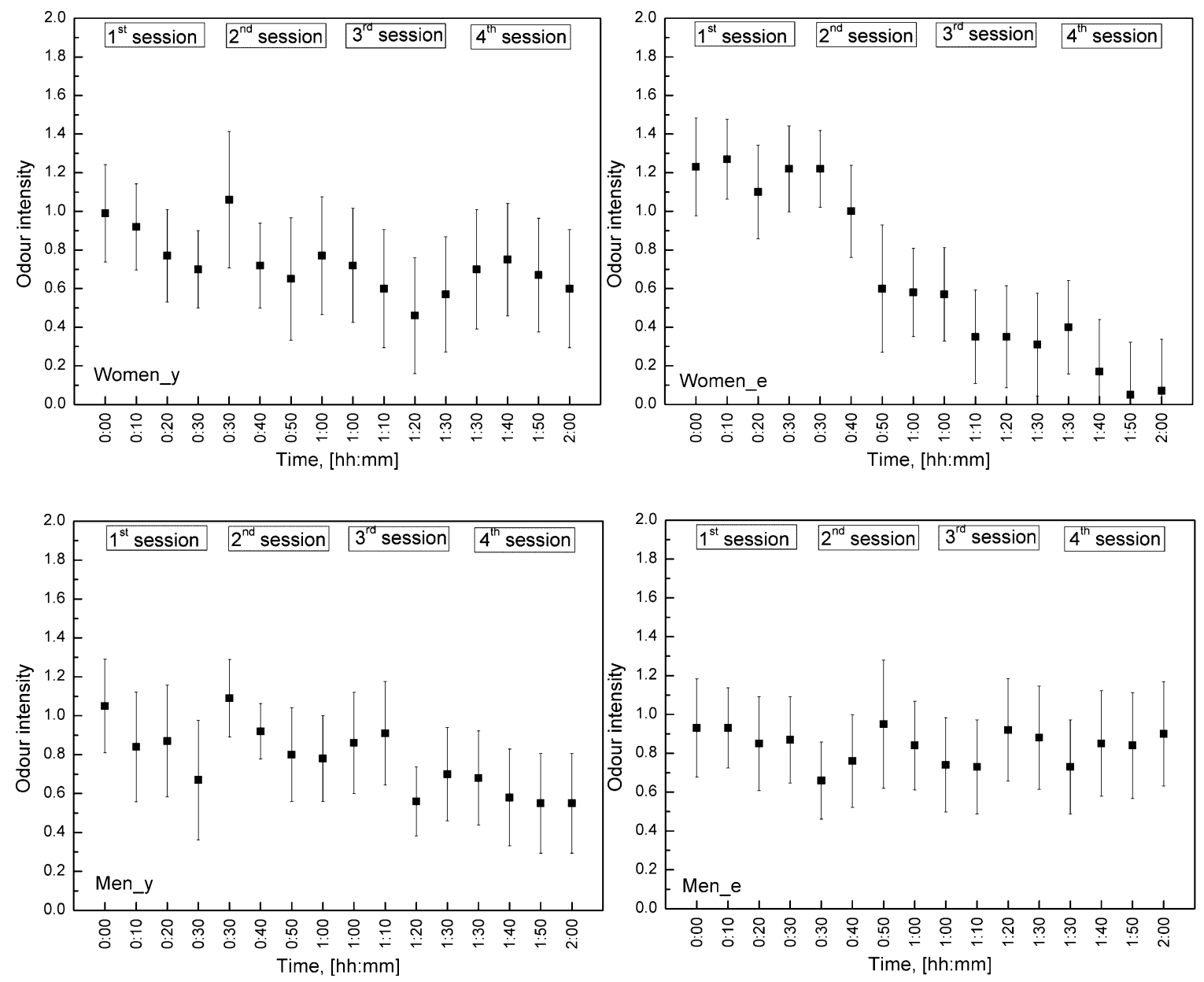

Figure 5. Odour intensity evaluation

It is interesting that young groups gave almost similar answers, while elderly persons evaluate completely different this IEQ parameter. No special odorant was used. Only the odour of building materials and equipment was evaluated. In case of elderly men group practically there is no difference between the odour intensity during the whole two hours measurements 
(no adaptation, no influence of ALTAIR PV), while the evaluation of the odour intensity by the elderly women group is higher at the beginning but shows a strong decrease in time. The reason of this decrease can be the adaptation on one hand and ALTAIR PV system on the other hand.

\subsection{Overall acceptance of the environment}

The mean values and the SEM of overall acceptance of the indoor environment by age and gender for different operation mode of the ALTAIR PV system (no operation, 30s, 20s, 10s time step of air flow direction changing) are presented in Figure 6.
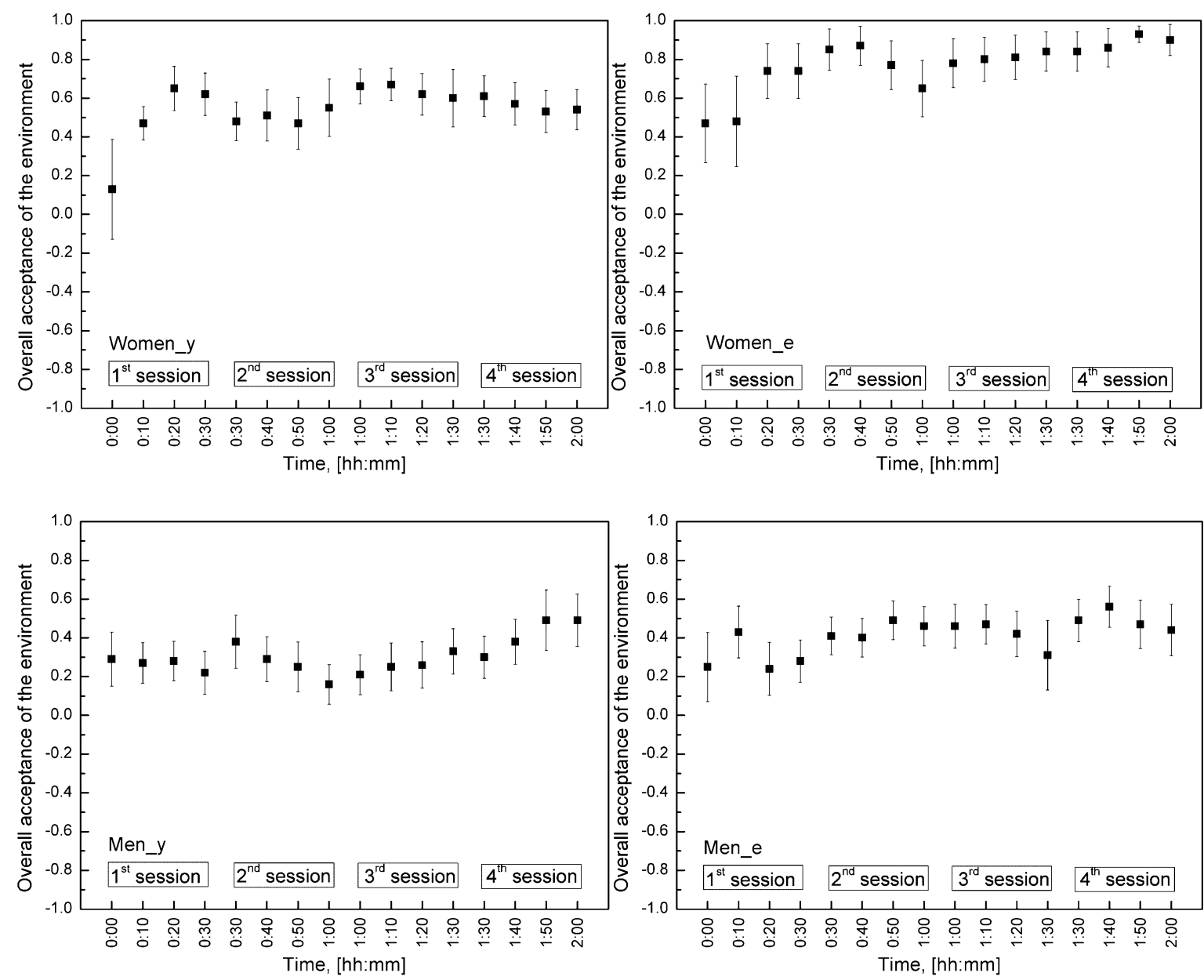

Figure 6. Acceptance of the indoor environment 
The overall acceptance of the indoor environment increased for all analysed groups. It is interesting that, in spite of high air- and mean radiant temperatures, the acceptance is between just acceptable and clearly acceptable for all groups. The lowest acceptance was found in case of elderly men, while elderly women gave the highest acceptance values.

\subsection{Evaluation of the air velocity and draught}

Air velocity was acceptable for $50 \%$ of the subjects in the first measurement session. In this session (with ALTAIR PV switched off) all dissatisfied subjects asked to increase the air velocity. With the ALTAIR PV system in operation the $70-80 \%$ of subjects appreciated the air velocity to be adequate. It can be observed that the percent of satisfied persons increased during the measurement in each group. It is interesting that the gradient of the trend lines is almost similar by gender (the gradient is higher in the case of women groups). Young groups were less satisfied with the air velocity.

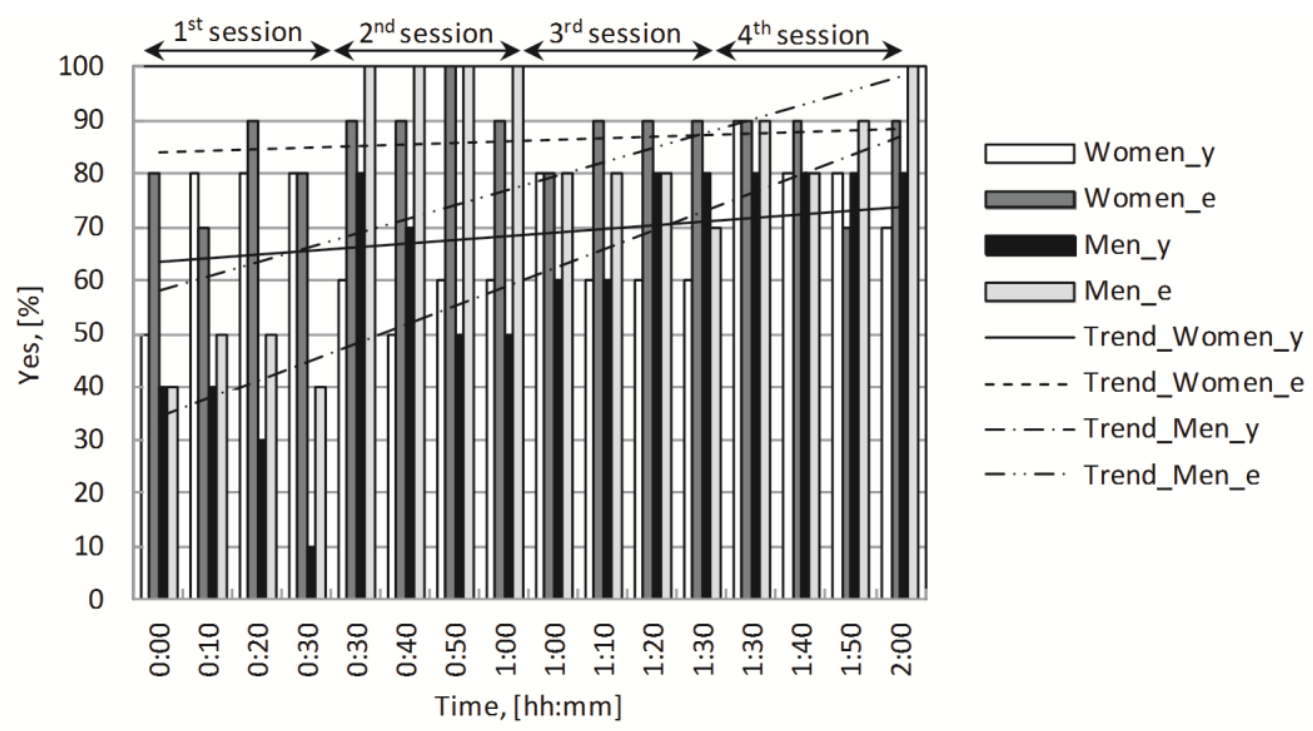

Figure 7. Percent of subjects satisfied with the air velocity

Furthermore, not each dissatisfied person asked the decrease of the air velocity (Table 5). 
Table 5. Number of persons who need higher air velocity

\begin{tabular}{|l|c|c|c|c|c|c|c|c|c|c|c|c|c|c|c|c|}
\hline Group & $0: 00$ & $0: 10$ & $0: 20$ & $0: 30$ & $0: 30$ & $0: 40$ & $0: 50$ & $1: 00$ & $1: 00$ & $1: 10$ & $1: 20$ & $1: 30$ & $1: 30$ & $1: 40$ & $1: 50$ & $2: 00$ \\
\hline W_y & 5 & 2 & 2 & 2 & 0 & 1 & 0 & 0 & 0 & 0 & 0 & 0 & 0 & 0 & 0 & 0 \\
\hline W_e & 2 & 2 & 1 & 2 & 0 & 0 & 0 & 1 & 2 & 1 & 1 & 1 & 1 & 1 & 1 & 0 \\
\hline M_y & 6 & 6 & 7 & 9 & 1 & 2 & 3 & 3 & 2 & 2 & 1 & 1 & 1 & 1 & 1 & 1 \\
\hline M_e & 6 & 5 & 5 & 6 & 0 & 0 & 0 & 0 & 1 & 0 & 0 & 1 & 0 & 0 & 0 & 0 \\
\hline
\end{tabular}

Practically no person experienced draught in the first measurement session, but with the ALTAIR PV system 70-100\% of subjects in all analysed groups reported draught sensation. The number of subjects who experienced draught correlates well with the answers given by subjects related to draught sensitivity. However, in the analysed warm environment, draught was interpreted by most subjects as a positive factor, which improved their thermal comfort sensation (Table 6).

Table 6. Number of persons for whom the draught sensation was embarrassing

\begin{tabular}{|l|c|c|c|c|c|c|c|c|c|c|c|c|c|c|c|c|}
\hline Group & $0: 00$ & $0: 10$ & $0: 20$ & $0: 30$ & $0: 30$ & $0: 40$ & $0: 50$ & $1: 00$ & $1: 00$ & $1: 10$ & $1: 20$ & $1: 30$ & $1: 30$ & $1: 40$ & $1: 50$ & $2: 00$ \\
\hline W_y & 0 & 0 & 0 & 0 & 3 & 4 & 4 & 4 & 2 & 4 & 4 & 3 & 3 & 2 & 2 & 2 \\
\hline W_e & 0 & 0 & 0 & 0 & 1 & 1 & 2 & 2 & 1 & 1 & 1 & 2 & 1 & 2 & 3 & 2 \\
\hline M_y & 0 & 0 & 0 & 0 & 0 & 1 & 0 & 2 & 1 & 2 & 2 & 2 & 1 & 1 & 2 & 1 \\
\hline M_e & 0 & 0 & 0 & 0 & 0 & 1 & 0 & 2 & 1 & 2 & 2 & 2 & 1 & 1 & 2 & 1 \\
\hline
\end{tabular}

\subsection{Evaluation of air freshness $\left(\mathrm{CO}_{2}\right.$ concentration $)$}

During measurements the $\mathrm{CO}_{2}$ concentration was measured and registered. The logged data have been analysed statistically. The variation of $\mathrm{CO}_{2}$ concentration during the 2 hours measurements is presented in Figure 8 using box chart diagram. 


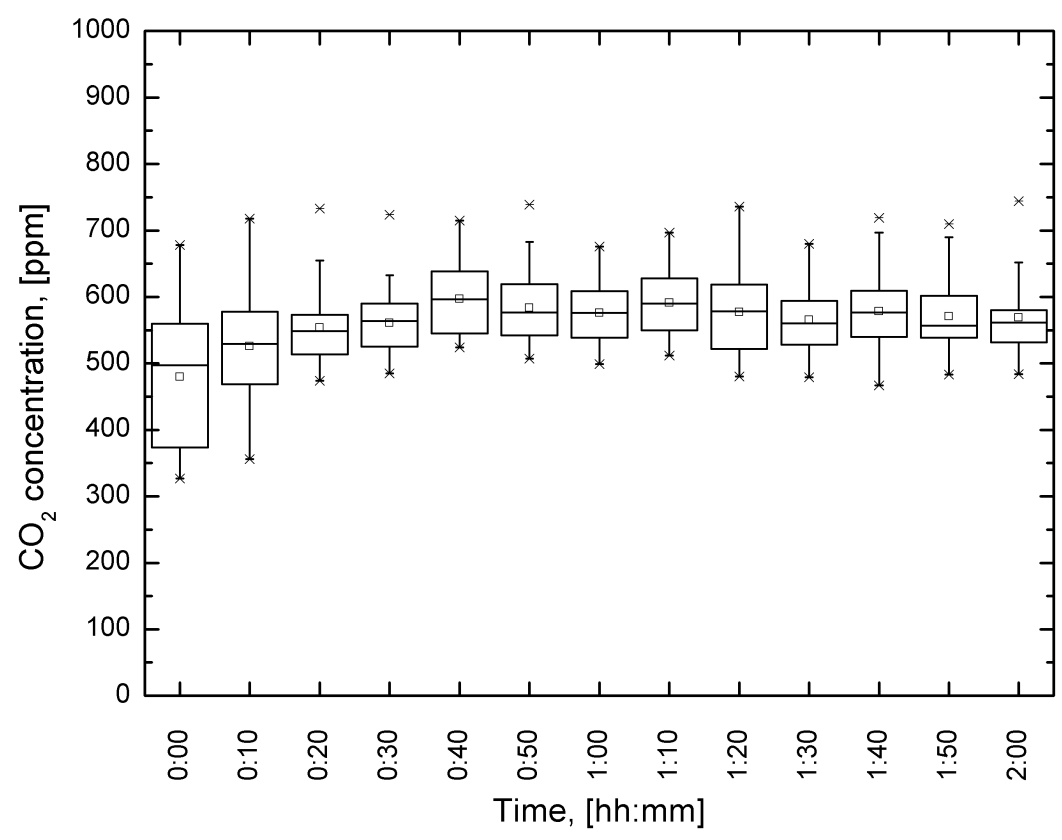

Figure $8 . \mathrm{CO}_{2}$ variation in the test room

The percent of subjects contented with the air freshness is shown by Figure 9.

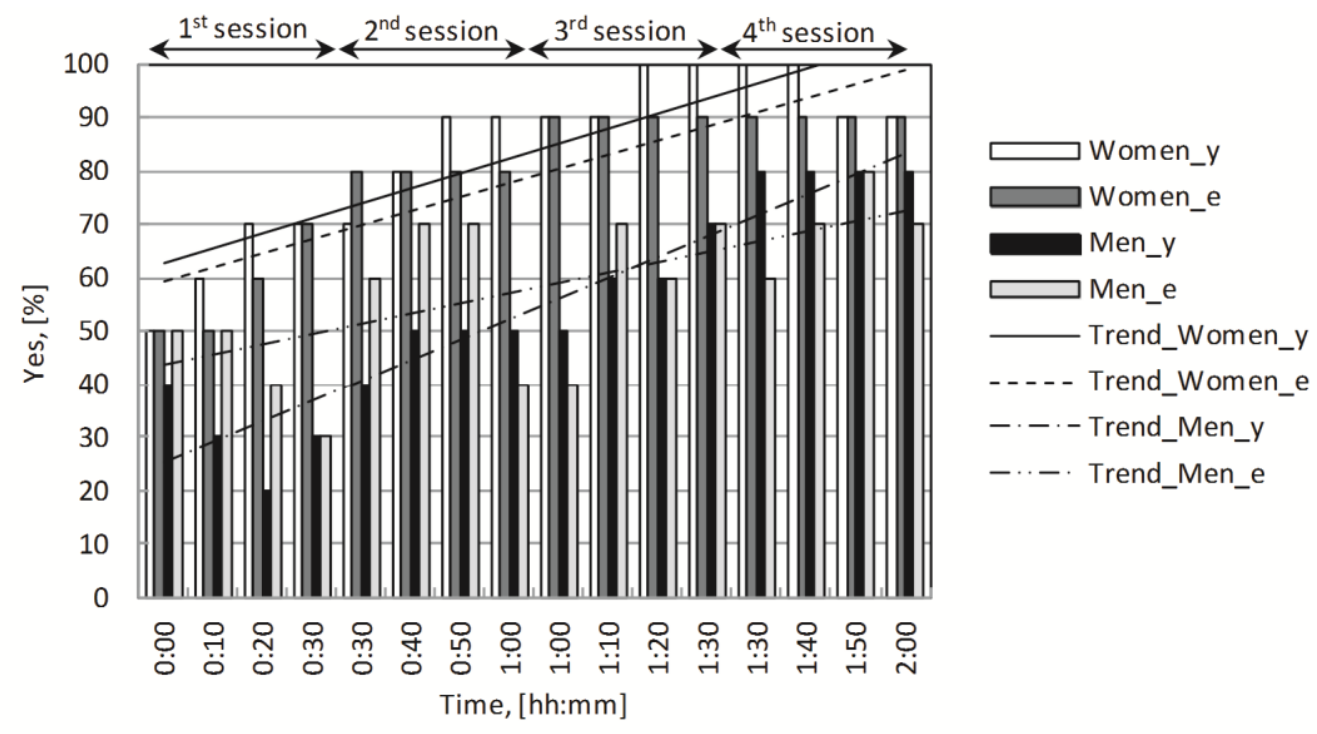

Figure 9. Percent of subjects contented with the air freshness

The number of subjects contented with the air freshness was the lowest in the first measurement session, even though the $\mathrm{CO}_{2}$ concentration was the lowest in this period (Figure 7). Analysing the responses, it can be observed that most subjects correlated the 
thermal comfort sensation with air freshness: "if the indoor environment is too warm, the air is not fresh enough".

\subsection{Evaluation of surface temperatures}

The surface temperature was relatively high during measurements. The aim of this question was to see whether the ALTAIR personalized ventilation system is able to neutralize the effect of high surface temperatures. It can be observed that the trend of the surface temperature acceptability increased when the ALTAIR PV was in operation, and the acceptability of the high mean radiant temperature was higher when the time step of air flow direction changing was lower (Figure 10).

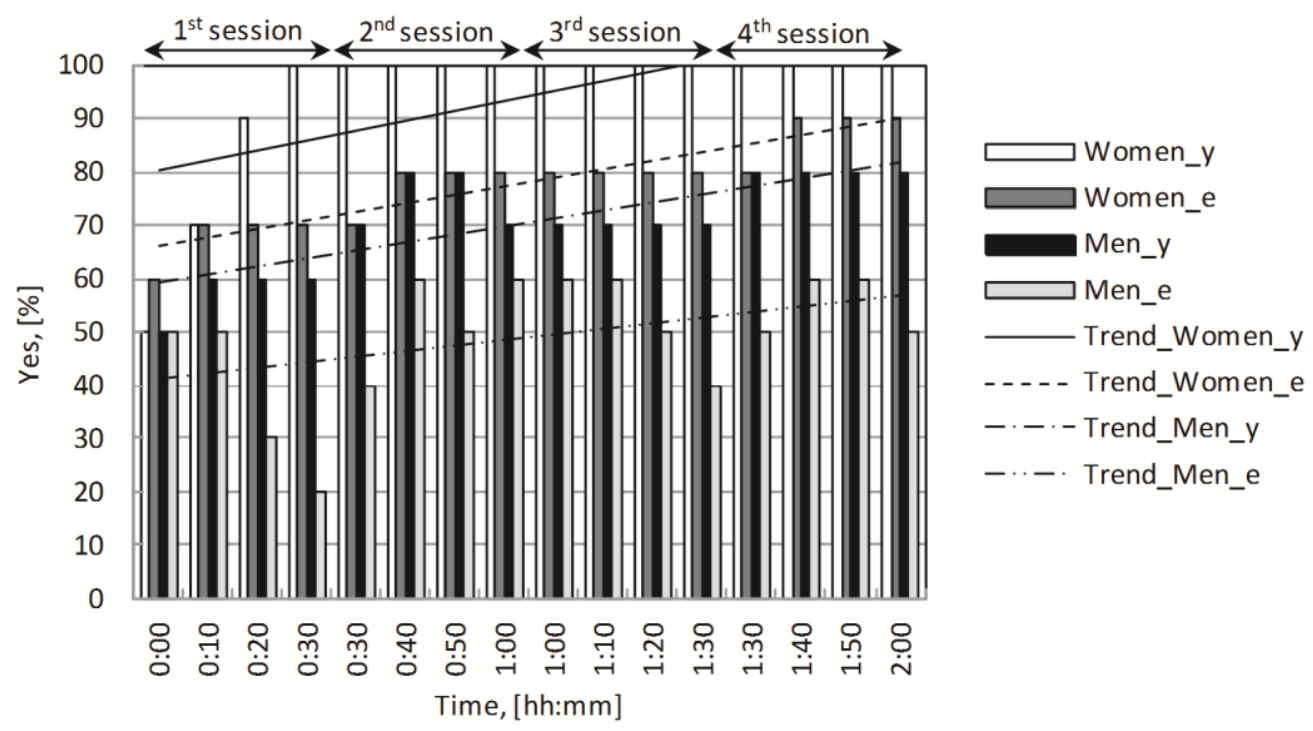

Figure 10. Percent of subjects satisfied with the surface temperatures

Personalized ventilation systems with advanced air distribution can be successfully used to improve the thermal comfort and indoor air quality in closed spaces, either alone or combined with total volume air distribution systems. 


\subsection{Uncertainties}

The uncertainties occurred during measurements are: uncertainties from repeated reading (Type A) and uncertainties from calibration certificates of instruments (Type B). These uncertainties should be combined and then the expanded uncertainty should be determined. For a coverage factor $k=2$, the level of confidence of expanded uncertainties is $95 \%$. The uncertainties of measured indoor parameters are presented in Table 7.

Table 7. Uncertainties of measured values

\begin{tabular}{|l|c|c|c|c|}
\hline \multicolumn{1}{|c|}{ Measured parameter } & \multicolumn{2}{c|}{ Standard uncertainties } & Combined & Expanded \\
\cline { 2 - 4 } & Type A & Type B & uncertainties & uncertainties \\
\hline Air velocity (without ALTAIR) & 0.0027 & 0.01563 & 0.01586 & \pm 0.03172 \\
\hline Air velocity (with ALTAIR) & 0.0071 & 0.02669 & 0.02673 & \pm 0.05525 \\
\hline Air temperature & 0.0899 & 0.2 & 0.2192 & \pm 0.438 \\
\hline Globe temperature & 0.0314 & 0.5 & 0.5010 & \pm 1.002 \\
\hline $\mathrm{CO}_{2}$ concentration & 13.82 & 30.63 & 33.61 & \pm 67.22 \\
\hline
\end{tabular}

Taking into account the accuracy of used probes and instruments, the PMV during measurements can slightly differ from the initially calculated 1.44 (without ALTAIR) and 0.84 (with ALTAIR) values.

\section{Conclusions}

The local comfort needs can be satisfied by using personalized ventilation systems. The effects of air flow direction changing on thermal comfort sensation was analysed by gender and age in a warm environment. It was found that: 
- in the case of first session of measurements (ALTAIR PV system switched off), the PMV value measured by TESTO 480 instrument (1.44) was validated by the young men, elderly men, elderly women group of subjects;

- the PMV value with the ALTAIR PV in operation measured by TESTO 480 instrument was 0.84 and this value was validated by the men groups;

- thermal sensation of young women subjects was significantly cooler, in comparison with the answers of the other groups;

- the odour intensity was evaluated similarly by young groups;

- in case of elderly men group practically there is no difference between the odour intensity during the whole two hours measurements;

- most subjects correlated the thermal comfort sensation with air freshness.

It was shown that advanced personalized ventilation systems can be successfully used in warm environments to improve the thermal comfort sensation. By changing sequentially the direction of the air flow around the head of occupants a supplementary cooling sensation is obtained (similarly to a handheld fan). Using this method in warm environments, the subjective thermal comfort sensation will be further improved. In the general equation of PMV the variation in time of the air velocity vector is not taken into account, therefore in warm environments the percent of dissatisfied persons will be lower than the calculated PPD. The next step of the research is to analyse the relation between thermal sensation and perception of air freshness in warm environments.

\section{References}

[1] Melikov AK. Personalized ventilation, Indoor Air; 2004, 14 (Suppl 7): 157-167.

[2] Melikov AK. Advanced air distribution, ASHRAE J.; 2011, November: 73-78. 
[3] Melikov A.K. Cermak, R. and Majer, M., Personalized ventilation: evaluation of different air terminal devices, Energ. Buildings; 2002, 34: 829-836.

[4] Zeng Q, Zhao R. Prediction of perceived air quality for personalized ventilation systems, Tsinghua Science and Technology; 2005, 10, 2: 227-232.

[5] Melikov AK. Advanced air distribution: improving health and comfort while reducing energy use, Indoor Air; 2016, 26: 112-124.

[6] Fanger PO, Melikov AK, Hanzawa H, Ring J. Air turbulence and sensation of draught, Energ. Buildings; 1988, 12: 21-39.

[7] Wang Y, Lian Z, Lan L. The effect of turbulence intensity on local skin temperature and subjective responses to draft, Energ. Buildings; 2011, 43: 2678-2683.

[8] Sun W, Tham KW, Zhou W, Gong N., Thermal performance of a personalized ventilation air terminal device at two different turbulence intensities, Build. Environ.; 2007, 42: 39743983.

[9] Zhang H, Huizenga C, Arens E, Yu T. Modeling thermal comfort in stratified environments, Proceedings of Indoor Air 2005, Beijing, 133-137.

[10] Toftum J, Nielsen R. Draught sensitivity is influenced by general thermal sensation, International Journal of Industrial Ergonomics; 1996, 18, 295-305.

[11] Arens E, Turner S, Zhang H, Paliaga G., Moving air for comfort, ASHRAE J.; 2009, May: 18-28.

[12] Koskela H, Heikkinen J, Niemela R, Hautalampi T. Turbulence correction for thermal comfort calculation, Build. Environ.; 2001, 36: 247-255.

[13] Kalmár F, Kalmár T. Alternative personalized ventilation, Energ. Buildings; 2013, 65: $37-44$.

[14] Kalmár F. Innovative method and equipment for personalized ventilation, Indoor Air; 2015, 25: 297-306. 
[15] Hensel H, Iggo A, Witt I. A quantitative study of sensitive cutaneous themoreceptors with C afferent fibres, J. Physiology; 1960, 153: 113-126.

[16] Darian-Smith I, Johnson KO. Thermal sensibility and thermoreceptors, The Journal of Investigative Dermatology; 1977, 69: 146-153.

[17] Parsons KC. The effects of gender, acclimation state, the opportunity to adjust clothing and physical disability on requirements for thermal comfort, Energ. Buildings; 2002, 34: 593599.

[18] Havenith A, Holmér I, Parsons K. Personal factors in thermal comfort assessment: clothing properties and metabolic heat production, Energ. Buildings; 2002, 34: 581-291.

[19] Indraganti M, Daryani Rao K. Effect of age, gender, economic group and tenure on thermal comfort: A field study in residential buildings in hot and dry climate with seasonal variations, Energ. Buildings; 2010, 42: 273-281.

[20] Choi J, Aziz A, Loftness V. Investigation on the impacts of different genders and ages on satisfaction with thermal environments in office buildings, Build. Environ.; 2010, 45: 15291535. 